\title{
Social Media and Reproductive Health - Communication Model of Adolescent Reproductive Health in Social Media
}

\section{Yanti Setianti, Susanne Dida, Lilis Puspitasari, and Aat Ruchiat Nugraha}

Department of Public Relations of Communication Science, Faculty of Bandung Padjajaran University

\section{Abstract}

Communication via social media has created a positive output on information dissemination in every aspect of life, including health. One of the social media functions is to support development by empowering the public in taking care of their own health and welfare. It is essential to develop an effective communication model for disseminating information on adolescent reproductive health. The rapid growth in the number of health reproductive information portals in the social media, the circumstances are creating a high selectivity on the right and correct information needed for the adolescent based on the particular condition in each region.

Keywords: Adolescent reproductive health, communication media, health communication, social media

\section{Introduction}

Health communication is a study of how to use communication strategies to disseminate health information, which can influence individuals and communities in deciding the right option in health management. In today's Internet environment, health information is easily accessible. With the rapid development of the Internet, particularly in the usage of social media among adolescents, has this led to greater awareness of health issues among adolescents in Indonesia? This paper examines the strategies of disseminating reproductive health information to the predominantly adolescent population in Indonesia.

WHO (2015) defines reproductive health as a state of complete physical, mental and social well-being; and not merely the absence of disease or infirmity, but also reproductive health processes, functions and system at all stages of life. The International Conference on Population and Development Programme of Action (POPIN, 2001) states that reproductive health implies that people are able to have a responsible, satisfying and safe sex life and that they have the capability to reproduce and the freedom to decide if, when and how often to do so. So, it can be said that adolescent reproductive 
health is the health condition concerning system, function, and reproduction process that adolescence has. The condition is not only being free from diseases or disabilities but also mentally and socio-culturally healthy.

The definition of adolescent, in general is the period of human transition from childhood to adulthood. An adolescent, according to World Health Organization (WHO), is an individual aged 10-19 year. United Nation, on the other hand, suggests that youth are individuals aged 15-24 years, later called "youth people" covering individuals aged 1024 years. Badan Kependudukan dan Keluarga Berencana (National Population and Family Planning Body, thereafter called BKKBN) in its program suggests that adolescentaare individuals aged 10-24 years old. Meanwhile Hurlock (1993) states that adolescence is the time of discovering self-identity, and the most difficult period in life.

Data from the Mitra Citra Remaja Persatuan Keluarga Berencana Indonesia Jawa Barat (or Mitra Citra Remaja, West Java Association of Family Planning Indonesia), which provides correct information on adolescence's reproductive health, show that in 2000-2005, there were 18,084 consultationz accessed through the service. The breakdown of the enquiries was as follows: 4945 asked for information on sexuality, which was made up of 980 on pre-marital sexual activity, 196 asking about virginity, 3752 on activities leading to sex, 222 on unwanted pregnancy, 17 developing HIV/AIDS, 27 developing sexually transmitted diseases, and 47 on abortion. The age range of the enquiries is 15 to 24 years old, with females dominating the consultation

The adolescents appeared to be unfamiliar with the reproduction process although the adolescent life in the villages and cities are becoming more permissive on premarital sex. The main issues related to the adolescent health reproductive were: premarital sexual activity leading to unwanted pregnancy, drop out from school because of pregnancy, irresponsible spouse, usage of contraceptives, abortion, infection from HIV/AIDS, sexually transmitted diseases, and drug abuse. Given this background, the Indonesian government and parliament have committed to a national program on improving the communication of reproductive health information to the predominantly adolescent population since 2000. The knowledge and experience of the organizers in this program, however, are considered as not being optimal.

in the field, have shown that adolescent has received inadequate information on reproductive health. Some of the adolescents have not considered yet the importance of reproductive health because the parents find that reproductive education is still a taboo to discuss. On the other hand, there is a tendency for adolescents to guard against the talk about reproductive health. This tendency creates a gap that later is covered by turning to social media, through Facebook, websites, and twitter to obtain information. Yuli, a coordinator of MCR (Mitra Citra Remaja or Adolescent Image Partner, an organization concerns on adolescent reproductive health) in Garut suggests that: 
"The way of delivering reproductive health information through twitter is limited; it cannot freely describe anything concerning the reproductive health. Unlike face-to-face communication getting right emotionally, twitter has limited number of words to deliver, so that all information we intend to deliver cannot get through in details, but like more a general review. "

MCR has disseminated information on adolescent health reproductive, as Yuli suggests that:

"We already gave the information on how to manage the health for adolescent, and then the age range of those adolescents, and how to manage their reproductive health.... managing reproduction; there are also programs that we carried out such as counseling, and road show to schools."

In adolescence, in addition to growth spurt, there are signs of secondary sex development, and the growth spurt ends. Female in this period is prepared for their role to be mother in the future. The nutrition in this period really has an impact on their future pregnancy and baby.

On the other hand, male reproductive organs are almost all visible: penis and scrotum. Other organs inside such as prostate gland are important in the sexual intercourse.

Yuli from MCR suggests that:

"The type of reproductive health information given is largely related to human organs with more aspects of human health, such as: vital organs, diseases, more to information aspects on health, this is what according to health I supposed. Yes, we sometimes connect things to religion. In religious belief, it is taught to take care of cleanliness for the sake of health, but we are focusing more on the health side."

The information on sexual intercourse has significant effect on adolescents, including those in Indonesia. As a result, there has been a revolutionary thought on premarital sex being done more freely. The assumption that adolescents in their school year and their young age will be free from genitalia infection should be abandoned, as this problem creates iceberg effects, creating concern among their parents and families.

Religious belief and reproductive health are really related closely. From religious point of view in Indonesia, reproductive health as one of the big health problem tends to be approached cautiously. 


\section{Research Objective}

To describe and examine an effective adolescent health reproductive information program via social media in Pasundan.

\section{Research Method}

This research uses a qualitative method, in which the author focused on solving actual problems as it happened during the research process. The author tried to frame phenomena and events as the main focal point and then described or recounted it as it made the result of the research valid at that particular time.

Qualitative method was a research procedure creating descriptive data in the form of written or spoken words by means of observing people and their behavior. Qualitative method used in this research was implemented based on the following considerations: firstly, it is easier to use in facing the double truth coming from the data; secondly, the method applies can reveal the nature of relationship between researcher and informant; thirdly, this method is sensitive and adjustable in confronting simultaneous influence and pattern of values.

Descriptive research studies the problems in society, as well as the procedures applied in the community and specific situations, including about the activities, attitudes, concepts and processes taking place and the effects of a phenomenon. In this study, the authors compiled data that had been collected regarding the issues, and then classified and analyzed descriptively. Descriptive research was used to be able to describe social phenomena occurring in the reality of life in a more systematic and complete way based on actual findings. The technique of collecting data used by the authors were interview with predetermined informants, documentation in which investigators collected documents coming from books, theses, journals, and articles related to health communications and adolescent, and document analysis coming from, media monitoring, electronic article, and photographs.

\section{Finding and Discussion}

\subsection{Adolescent Reproductive Health Communication Model in the Land of Pasundan}

The plan of an effective local genius based-health communication model regarding the knowledge of reproductive health will be implemented among adolescents. General 
studies on health communication through social media show that it plays an inadequate role in changing the audience behavior. On the other hand, interpersonal communication, in a limited way, is considered as having more capabilities of reaching the attitude and behavioral of audience.

Health communication requires various parties to cooperate in order to be successful, for example the cooperation between non-governmental health concern organization and health ministry. Health communication should receive more serious attention from the government for the objective of having Indonesian people concern with their own health.

At cultural level, it is crucial to place taboo where it is supposed to be, and to introduce a new consciousness of reproductive health education as it intended rather than a lesson of sexual intercourse. Nowadays there are some parties considering reproductive health education similar to telling the adolescents to have sexual intercourse, and disagreeing with whatsoever in the implementation of reproductive health education.

At the family level, many parents feel that it is a taboo to raise the issue of reproductive health to their teen children. An effective communication is needed to deliver accurate information on reproductive health.

It is not a simple task to urge the government to establish cultural change; nevertheless, government has already put it into a health law, Republic Indonesia Law no. 36 year 2009, article 136 and 137, despite a far-reaching implementation.

The media, meeting the requirements of interaction, are Internet and telephone. There are many adolescents having an introvert tendency, turning to Internet for a consultation with volunteers, keeping them anonymous. In addition to having a therapeutic communication, Internet plays a significant role to provide information needed on reproductive health.

Internet, serving as health information provider, has some advantages such as: relatively cheap cost, more comfortable for users, reducing health service costs, easier access to overcome isolated patients, satisfying the need for quick information, reducing stigma, increasing user and provider intervention.

Internet is the electronic network, interconnecting human beings all over the world through computer, and one of the most important components in the globalization era. As the communication aspect, internet serves to be information provider and promotional facility. Internet has an ability of connecting an individual to another from any location in the world; by means of email to send data or written messages, chatting facilities, and Usenet or forum. Forum is a facility provided in the Internet to share information and thought about topics through electronic bulletin. Forum is created in such a way that the users can send multiple messages on a particular topic. 
HEALTH COMMUNICATION

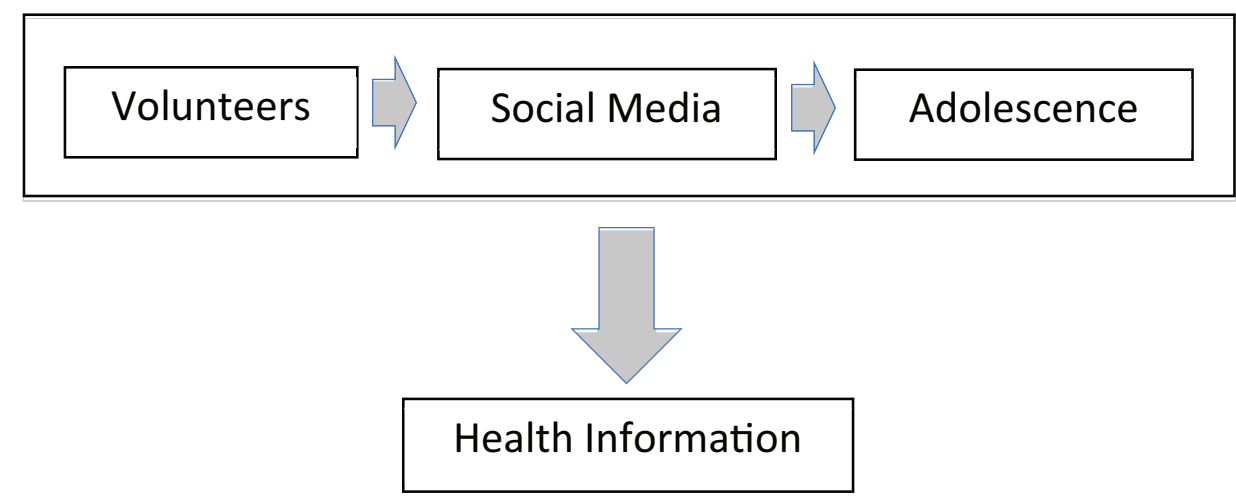

Figure 1: Health Communication Model.

Internet is connected to hundreds of library catalogues, in which users would be able to do research on thousands of databases that is opened for public view through the services provided by companies, governments, or non-profit organizations. Internet users would be able to use all the information gathered for their businesses or to find their business environment including competitors and stakeholder's interests. Online buying is still a rare sight in Indonesia as only sellers, service providers, and information (news) providers are available. There are so many functions and uses of Internet to be discovered, especially in the term of communication. Nowadays, people would be able to communicate through a free telephone over the Internet all over the world by using VOIP (Voice over Internet Protocols).

The anonymity of information provider has created a lot of less credible web-based health information. This obstacle can be dealt with using a sharper mind in accessing health information and communicating therapeutically, using official websites only, such as Mitra Citra Remaja website. Direct counseling feature is available over the website, facebook, twitter, while telephone and face-to-face meeting features are also available offline.

\section{Conclusion}

1. The adolescents are still poorly aware of reproductive health as their parents still considered it as a taboo topic to discuss.

2. Social media is the most widely used media for adolescents in searching for reproductive health information.

Internet makes life easier for people, especially in finding any information about anything that they need to know, including adolescent reproductive health information. Through the Internet, adolescents would be able to make counseling with volunteers from MCR, who always be there accompanying those in the counseling sessions. 
By accompanying adolescents, they have to counsel, the continuity of the problem should be able to oversee. Volunteers usually have an advance communication through Internet, on Facebook or twitter with the adolescents in counseling session.

In counseling session, volunteers use the same technique as that the real world of communication. In communicating, people will deliver messages on various contexts and conditions, both verbally and non-verbally. The health communication model in this research can be described in the figure above.

\subsection{Suggestion}

1. Government should have a socialization program towards the public, especially in rural area, on the importance of adolescent reproductive health education.

2. Type of local genius must be applied in order to assist the socialization process for adolescent reproductive health knowledge.

\section{References}

[1] Basrowi and Sukidin, "Metode Penelitian Kualitatif; perspektif Mikro," Surabaya; Insan Cendikia, 2002.

[2] J. Creswell, Qualitative Inquiry and Research Design: Choosing Among Five Traditions, Sage Publications, USA, 1998.

[3] Glanz, "Rimerdan Lewis.. Health Behavior and Health Education," San Francisco; Jossey-Bass a Willey imprint, 2002.

[4] Alcalay. Karsnehendudan and Rina., Health Communication, Sage Publications, New Delhi, 2001.

[5] Deddy. Mulyana, Metode Penelitian Komunikasi, Metode Penelitian Komunikasi, Bandung. Remaja Rosdakarya, 2009.

[6] United Nations Population Information Network/POPIN, (2001) Guidelines on Reproductive Health, Accessed on 8 January 2015, URL: http://www.un.org/popin/unfpa/taskforce/guide/iatfreph.gdl.html. 